\title{
The design of UV-LED Control System
}

\author{
Mi Tao ${ }^{1, a}$, JinyaoLi $i^{2, b}$ \\ ${ }^{1}$ Electrical Engineering and Automation, Beijing Institute of Graphic Communica- \\ tion,Beijing ,102600, China \\ ${ }^{2}$ Electrical Engineering and Automation, Beijing Institute of Graphic Communica- \\ tion,Beijing ,102600,China \\ aemail:mitao0215@126.com, bemail:jinyaoli@bigc.edu.cn
}

Keywords: UV-LED drying device; AT89S52; PWM; PID

\begin{abstract}
Aiming at the development trend of printing industry, describes the new green UV-LED drying equipment, design and development of AT89S52 lighting control system based on MCU, and use the PWM dimming circuit and incremental PID control algorithm, a distributed computer lighting control system, the method can make the system keep stable. The system isvalidated by experiments, achieved satisfactory control effect, and has been applied to theUV-LED drying device, the system also applies to the field of printing, coating and adhesive.
\end{abstract}

\section{Introduction}

UV-LED printing drying technology is a green drying technology of energy saving and environmental protection, economic. Green printing is refers to has a little influence on the ecological environment, less pollution, saving resources and energy of printing methods, involving the printing production process [1]. Over the years, our country actively implement the strategy of sustainable development, environmental protection should be put in an important strategic position, and comprehensively promotetheenergy-savingemission reduction. UV-LED isthe UV-LED diode (Ultraviolet light emitting diode), whose wavelength is $315 \mathrm{~nm} \sim 450 \mathrm{~nm}$. It is a kind of solid cold light source, not through the heat makes objects heat and light, but by electricity can directly convert light energy, following the incandescent lamp, fluorescent lamp and high pressure discharge lamp (HID) after the fourth generation light source of the utility model [2]. UV-LED printing drying technology is a kind of energy-saving, environmental protection, economic green drying technology, it is an important application in the development of LED light source, is led from the light source for lighting purposes turn for industrial uses light source is the key step.

\section{The hardware design of the system}

\subsection{The overall design and working principle}

This system is based on AT89S52 lighting control system [3][4].AT89S52 is a low-power, high-performance cmos8 bit microcontroller, with $8 \mathrm{~K}$ bytes of in system programmable flash memory. Using Atmel's high-density nonvolatile memory technology manufacturing, fully compatible with the industrial 80C51 product instructions and pin. The on-chip Flash allows the program memory to be reprogrammed in system is also suitable for conventional programming. In a single chip, with the versatile 8-bit CPU with in system programmable flash. AT89S52 makes for many embedded control system provides a highly flexible and cost-effective solution. 


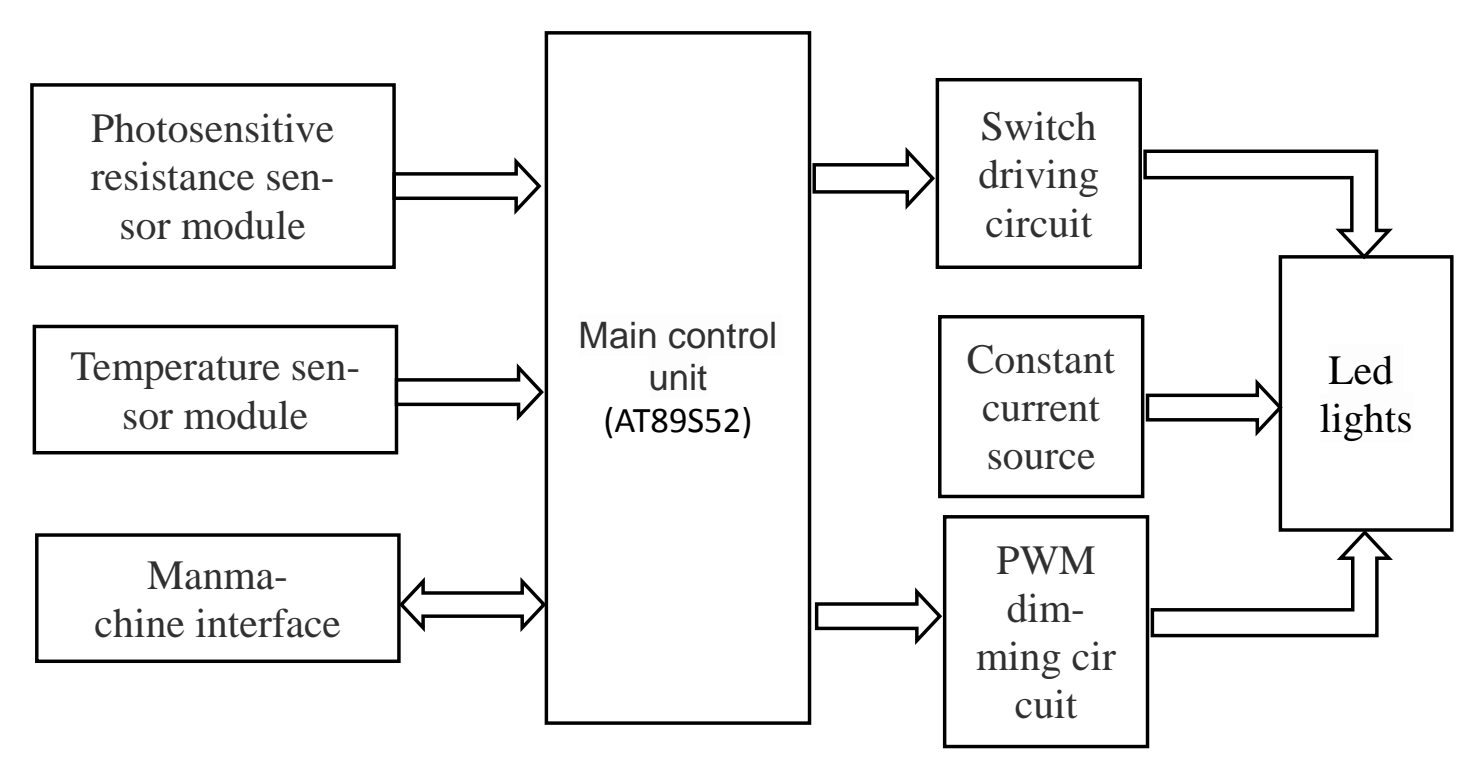

Figure 1 Block diagram of control system hardware

\subsection{Models of control system}

With the LED widely used and networking, cloud computing and other new technology bureau of ceaseless emerge in large numbers of development, led by the more and more and smart photo control system combined, so that higher levels of meet the needs of modern society, people more and more high lighting needs.

At present, the intelligent lighting control system research and application has made some progress, and there are a lot of good products, from the technical to the hardware is greatly improved compared to the previous, industrial production has some mature products put into use. The intelligent lighting control system control signal vector classification can control signal line, power line carrier control and wireless network control etc[5].

LED lighting control system block diagram shown in figure 2. Among them, photos ensitivemodule uses negative feedback to improve the control precision of design, performance, lighting control system response time.

UV-LED lighting control system principle: Given the standard voltage signal $U_{n}$, the power adapter (standard called LED control device, namely first function block, The transfer function is $\mathrm{f}_{1}\left(\mathrm{U}_{\mathrm{n}}, \mathrm{R}, \mathrm{L}, \mathrm{C}\right)$, the state space expression is $\left.\mathrm{F}_{1}\right)$, into standard current signal control In; Indium and output system that light signals of the sensing negative feedback signal $\mathrm{I}_{2}$ compares the sensing module transfer function design for $\mathrm{f}_{4}\left(\mathrm{LL}_{\mathrm{L}}\right)$ and the state space expression for $\mathrm{F}_{4}$ ), the actual control signal $\triangle \mathrm{I}, \triangle \mathrm{I}$ after appropriate circuit processing and conversion (deal with conversion module of the transfer function $f_{2}(\triangle I, R, L, C)$, the state space expression of the design for the $\left.F_{2}\right)$. The actual control of the voltage signals $U_{1}$; $U_{1}$ through the power adapter (the transfer function is $f_{1}\left(U_{n}, R, L\right.$, C) state space representation of the design for $\mathrm{F}_{5}$ ) processing, get the final actual control current $\mathrm{I}_{1}$; I1 directly to LED lamp, issued light (control object $\mathrm{LL}_{\mathrm{L}}$ ), the electrical to optical transfer function design of $\mathrm{f}_{3}\left(\mathrm{I}_{1}\right)$ state space representation for the $\mathrm{F}_{3}[6]$.

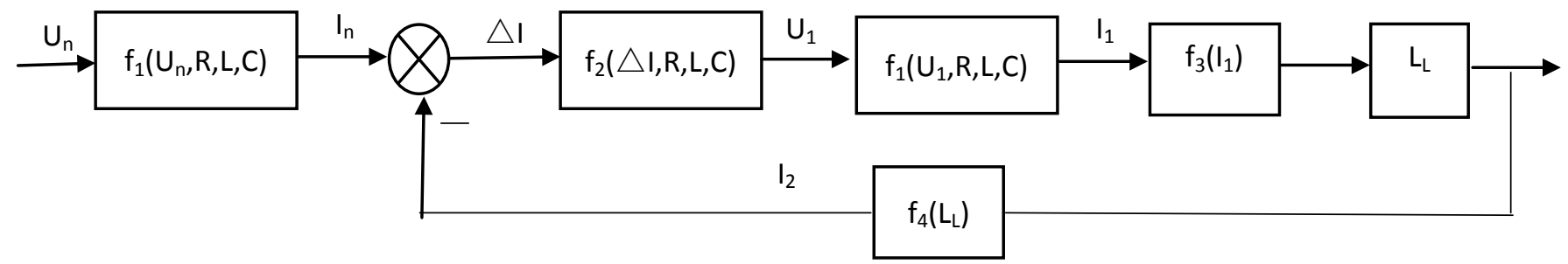

Figure 2 LED lighting control system block diagram 


\subsection{System hardware design}

Pulse width modulation (PWM) is a kind of analog control mode, according to the corresponding load changes to modulation transistor gate or base of the bias to achieve switch regulated power output transistor and transistor guide changes through time. This way can make the output voltage of the power supply remains constant in work condition change, the microprocessor of the digital output to control a very effective technique for analog circuits. PWM control technology in its control is simple, flexible and dynamic response of the advantages of a power electronics technology, the most widely used method of control

We adopt the pulse width modulation (PWM) to adjust the brightness of the LED lamp, according to the values of the lighting to adjust the accounting for empty ratio (fixed), the electronic switch constantly closing and disconnecting, the breaking frequency can reach very high to control the average current flowing through the led to reach LED brightness control.

\section{System software design}

The control system uses a control mode of the [7] as the current field of industrial control, digital PID controller. PID controller is a linear controller, it will set the value and between the measurements of the percentage deviation (P), integral (I) and differential (d) by linear combination constitutes the control volume, the object control. PID control algorithm can be divided into position PID algorithm and the incremental PID control algorithm. Due to the presence of certain disadvantages position type PID algorithm and incremental PID control algorithm with error action of small advantages; manual / automatic switch has small impact, easy to realize bumpless transfer; formula does not need to accumulate, incremental $U(\mathrm{k})$ is determined only with the k nearest sampling value, so easily by weighted processing and obtain better control effect [8] control. Therefore, this paper selects the incremental PID control algorithm, the classical digital incremental PID formula:

$$
\begin{aligned}
& \Delta \mathrm{u}_{\mathrm{n}}=\mathrm{u}_{\mathrm{n}}-\mathrm{u}_{\mathrm{n}-1} \\
& =\mathrm{K}_{\mathrm{P}}\left[\left(\mathrm{e}_{\mathrm{n}}-\mathrm{e}_{\mathrm{n}-1}\right)+\frac{\mathrm{T}}{\mathrm{T}_{\mathrm{I}}} \mathrm{e}_{\mathrm{n}}+\frac{\mathrm{T}_{\mathrm{D}}}{\mathrm{T}}\left(\mathrm{e}_{\mathrm{n}}-2 \mathrm{e}_{\mathrm{n}-1}+\mathrm{e}_{\mathrm{n}-2}\right)\right] \\
& =\mathrm{K}_{\mathrm{P}}\left(\mathrm{e}_{\mathrm{n}}-\mathrm{e}_{\mathrm{n}-1}\right)+\mathrm{K}_{\mathrm{I}} \mathrm{e}_{\mathrm{n}}+\mathrm{K}_{\mathrm{D}}\left(\mathrm{e}_{\mathrm{n}}-2 \mathrm{e}_{\mathrm{n}-1}+\mathrm{e}_{\mathrm{n}-2}\right)
\end{aligned}
$$

The proportional coefficient $K_{P}$; integral coefficient $K_{I}$; differential coefficient $K_{D} ; K_{I}=K_{P} \frac{T}{T_{I}}$; $\mathrm{K}_{\mathrm{D}}=\mathrm{K}_{\mathrm{P}} \frac{\mathrm{T}_{\mathrm{D}}}{\mathrm{T}}$ 。

Proportional component instant reflects the proportion of control the deviation signal of the system, deviation once generated, the controller immediately control effect, to reduce the bias. The integral is mainly used to eliminate static error and improve the system of no difference. Integral effects depend on the integral time constant TI, the larger TI, integraleffect is weak, whereas the more strong. Differential loop energy-saving reflect the deviation signal variation trends (rate of change), before and in the deviation signal value becomes too large, in the system into an efficient early correction signal, so as to speed up the action speed of the system, reduce the adjusting time. Type (1) is prepared on the basis of PID control software.

According to the analysis of the task, the system software design process is shown in Figure 3. 


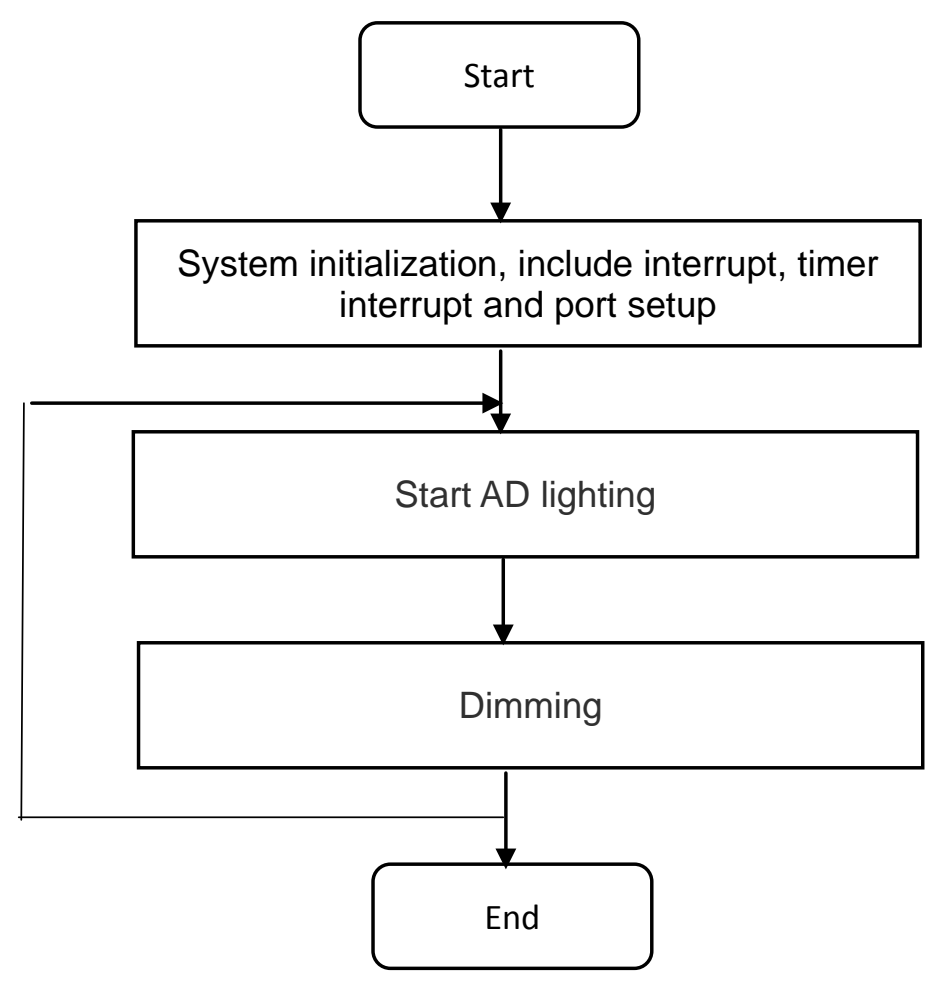

Figure 3 Flow chart

\section{Conclusion}

The system is based on AT89S52 lighting control system, a distributed computer light control system. At the same time, in the algorithm by incremental PID control algorithm, the system effectively solves the lighting control system problems. At present, the control method has been applied to the UV-LED drying device. The running results show that control system has achieved the expected goals in process control and the system advanced technology, low cost, energy-saving emission reduction, convenient management effect up to good economic benefits.

\section{References}

[1] Environmental development center of printing and environmental protection department.Green printing and China Environmental Labeling[M].2012.

[2] Tiehong Li. New opportunities for LED UV curing [J]. Print magazine.2014(11)58.

[3] Wang Rui. Application of LED UV technology in the printing field [J]. Printing today. 2013 (11) 61-62.

[4] Zhengsong Jia, Design of intelligent lighting control system based on single chip microcomputer[J]. Modern electronic technology.2009 304(17)105-107.

[5]Zhenghong Shen and so on. Research on the model of LED lighting control system[J].Chinese lighting appliance. 2013(12)6-9.

[6] Gou Ge and so on.Analog circuit and digital circuit[M].Electronics Industry Press. 2009.

[7] Erfu Duo and so on. Modern control system [M]. Electronics Industry Press.2011.

[8]Tieqiang Chen and so on. Development and experiment research of PID constant temperature control system based on AT89S52 MCU[J]. Mechanical and electrical engineering technology. 200938(09)52-55. 